\title{
Topical Pharmacotherapy for Actinic Keratoses in Older Adults
}

\author{
Piergiacomo Calzavara-Pinton $^{1}{ }^{1} \cdot$ Irene Calzavara-Pinton $^{1} \cdot$ Chiara Rovati $^{1} \cdot$ Mariateresa Rossi $^{1}$
}

Accepted: 10 January 2022 / Published online: 14 February 2022

(c) The Author(s) 2022

\begin{abstract}
Actinic keratosis is caused by excessive lifetime sun exposure. It must be treated, regardless of thickness, because it is the biologic precursor of invasive squamous cell carcinoma, a potentially deadly malignancy. Physical ablative techniques such as cryotherapy, lasers, and curettage are the most used treatments for isolated lesions. Multiple lesions are treated with topical drugs, chemical peelings, and physical techniques. Drug preparations containing diclofenac plus hyaluronate, aminolevulinic acid, and methyl aminolevulinate and different concentrations of imiquimod and 5-fluorouracil are approved for this clinical indication. All treatments have a good profile of efficacy and tolerability although there are relevant differences in the clearance rate, tolerability, and type and frequency of adverse effects. In addition, they have very different mechanisms of action and treatment protocols. No differences in the efficacy and tolerability were found in older patients compared with younger patients, therefore no dose adjustments are needed. That said, older patients often need to be motivated to treat actinic keratoses and a careful attention to expectations, needs, and preferences should be used to obtain the maximal adherence and prevent treatment failure. This goal can be achieved with a careful evaluation not only of published efficacy, toxicity, and tolerability data but also of practical topics such as the frequency of daily applications, the overall duration of therapy, and the need for a caregiver. Finally, particular attention must be paid in the case of frail patients and immunosuppressed patients.
\end{abstract}

\section{Key Points}

Actinic keratosis is a frequent skin disorder of older subjects and it is the biological precursor of invasive squamous cell carcinoma.

All actinic keratoses should be treated because the risk of malignant progression is not predictable on the basis of the clinical thickness and size. In addition, if multiple lesions are present, the surrounding photodamaged skin should be treated as well because it harbors a "cancerization field".

Several drug treatments with different mechanisms of action, pharmacological properties, protocols, and efficacy and safety profiles are available and the clinician can individualize the treatment on the basis of the preferences and needs of the patient in order to achieve the optimal adherence and the best therapeutic result.

Piergiacomo Calzavara-Pinton

piergiacomo.calzavarapinton@unibs.it

1 Dermatology Department, University of Brescia, Piazza Spedali Civili 1, 25124 Brescia, Italy

\section{Introduction}

Actinic keratosis (AK) is a chronic skin lesion of oncologic interest as it bears the potential to progress to invasive squamous cell carcinoma (SCC). The only known cause is excessive lifetime exposure to ultraviolet (UV) radiation, therefore it primarily affects older adults with a fair phototype. The latitude and altitude of the geographical location and the individual photoprotective behaviors are among the main risk factors [1].

In Europe and the USA, the estimated overall prevalence spans between 6 and 26\%, with a higher prevalence in southern countries [2]. The incidence has grown rapidly and steeply over the past few decades and the treatment has become a relevant burden for healthcare systems [3]. It has been hypothesized that the great increase in the occurrence of this disease could be linked to lifestyle reasons, for instance, people that are now aged 70 years or more have lived most of their lives in those years in which tanning salons and "sun holidays" became increasingly popular, in the absence of a strong and shared focus in the general population on the importance of photoprotection and skin cancer prevention.

Clinically, AKs present with erythematous, sometimes pigmented, lesions with a scaly or keratotic surface [4] 
on sun-exposed areas of the body, such as the head, the neck, the hands, and the forearms [5]. Visual inspection is usually enough for diagnosis and non-invasive diagnostic techniques (e.g., dermoscopy, in vivo confocal laser scanning microscopy, and optical coherence tomography) have strongly improved the diagnostic accuracy if clinical findings are ambiguous. An incisional biopsy is sometimes needed for infiltrated, painful, inflamed, and/or hyperkeratotic lesions that are suspicious for SCC [6-9].

Microscopic examination shows dysplasia and architectural disorder of the epidermis. Keratinocytes of the basal layer are abnormal and variable in size and shape with nuclear atypia and altered cellular polarity. These alterations may extend upward toward the granular layer, which may be thinned. Hyperkeratosis and parakeratosis, and irregular acanthosis are other common findings. A few histopathological variants have been identified, including hypertrophic, atrophic, acantholytic, pigmented, proliferative, and Bowenoid subtypes.

The Roewert-Huber histological classification system grades AK lesions based on the extent and upward presence of epidermal atypical keratinocytes (AK I-III) [10], whereas the PRO I-III histologic score classifies AKs according to the basal downward growth patterns (crowding, budding, and papillary sprouting) of the atypical keratinocytes [11]. The latter was recently found to be more predictive in terms of a progression risk than the Rowert-Huber classification [11]. However, neither classification has been clinically validated.

A few authors classify $\mathrm{AK}$ as an in-situ tumor because there is a disease continuum extending from $\mathrm{AK}$ to $\mathrm{SCC}$, a potentially lethal tumor with the potential for invasion of the tissues underlying the skin and of producing distant metastases. Indeed, almost all SCCs are found to be associated with AKs and as for histopathological characteristics, the cell cytology and mutational profile of the two diseases are quite similar [12]. Others classify $\mathrm{AK}$ as a pre-cancerous lesion because the progression rate is low, from 0 to $0.075 \%$ per lesion-year, whereas the rate of spontaneous regression of single lesions is high, from 15 to $63 \%$ after 1 year [13]. Unfortunately, there is no reliable morphologic feature that can predict with certainty the evolution of the single individual lesion [2].

The I-III Olsen score is based on the perceptible thickness, and it is widely used for treatment planning in clinical practice. However, it lost its prognostic value when it was demonstrated that the malignant evolution is not an orderly progression from Olsen I to II and then to III and finally to SCC but all lesions, regardless of their thickness, have the potential to progress to SCC [14]. In addition, recent research has demonstrated that the Olsen score does not match the histologic Roewert-Huber score [2] and the PRO score [11].

Although it has no prognostic value for the individual lesion, the number of lesions in a given skin area is an important prognostic factor because the risk of developing a SCC is greater if multiple lesions are present. According to a commonly used but arbitrary threshold, the classification as "isolated AKs" is represented by fewer than five AKs in a given body area, whereas "multiple AKs" means that there are five or more AKs in a defined body area [6-9].

The AKASI (Actinic Keratosis Area and Severity Index) [15] is a quantitative tool with a $0-18$ scale to assess the severity of AKs of the head and it has been proven to be reliable for stratifying the risk for developing invasive SCC [16]. For the calculation of such an index, the number of lesions and other factors such as size, distribution (isolated or confluent), degree of inflammation, thickness, and location (scalp, forehead, left and right side of the face) [6] are taken into account. Finally, multiple lesions and high AKASI scores are predictive of a high risk of development of new AKs and frequent recurrences after treatment [6] as, under these conditions, it is likely that subclinical lesions are also present [17] and the non-lesional surrounding skin harbors keratinocytes with a heavy mutational burden, the "field of cancerization" [6-9].

\section{Treatment Options for AKs}

In agreement with the improvements in the knowledge of the pathogenesis and prognosis of AKs, the therapeutic paradigm of the disease was switched from "treatment of thick AKs only" to "treatment of all AKs, regardless of thickness" [18] and, if multiple lesions/high AKASI scores are present, to "treatment of all AKs regardless of thickness + treatment of the whole surrounding cancerization field" [6-9]. Isolated lesions are usually treated with lesion-directed interventions aiming at removing AKs mechanically (curettage and shave surgery) or destroying them thermally with controlled cold (cryotherapy) or heat (laser and electrosurgery) burns.

Physicians use one or more of these techniques according to their own experience, skill, preference, and availability of technology. However, it is common evidence that cryotherapy and curettage are the most used in daily practice because of the practical advantages: they are easy to use and inexpensive. In addition, they allow the treatment of many lesions in a single session, regardless of their thickness, as local anesthesia is not required and, in the case of cryotherapy, there is no bleeding [6-9].

Lasers are also very popular: ablative laser treatment can be offered for all AKs, regardless of thickness. Conversely, non-ablative laser treatments should be offered only for grade I-II Olsen AKs [19].

Surgical removal has a limited role for AK management: it is the first line of treatment only if visual inspection and dermoscopy cannot rule out the progression to SCC, particularly in immunosuppressed patients. Surgery is preferred also in the case of AKs of the legs in older subjects because, 
due to skin thinness, second-intention healing may be very slow.

The spectrum of available field-directed treatment options is broad and includes drug preparations containing different active ingredients (Table 1), physical ablative treatments, and chemical peelings.

The first approved drug for field treatment was 5-fluorouracil (5-FU), in 1962: it is a pyrimidine analog that competitively inhibits the enzyme thymidylate synthase, thereby creating a thymine deficiency and resulting in inhibition of deoxyribonucleic acid synthesis and, finally, in cytotoxicity. It also inhibits, to a lesser extent, the formation of ribonucleic acid. Treatment is rather selective for AK spots because the cytotoxic effects are more marked in rapidly growing cells [20].

Imiquimod (IMI) is a Toll-like receptor 7 agonist that activates immune cells: it stimulates the innate and adaptive immune responses and induces cytokine production and antitumor immune responses that are selectively directed against mutated keratinocytes [21]. Diclofenac sodium is a non-steroidal anti-inflammatory drug: its mechanism of action is related to the inhibition of the cyclo-oxygenase pathway, leading to reduced prostaglandin E2 synthesis, anti-inflammatory and anti-angiogenic effects, and possibly anti-proliferative and apoptosis-inducing mechanisms [22]. In the commercial preparation diclofenac is combined with sodium hyaluronate (DHA).

Aminolevulic acid (ALA) and methyl aminolevulinate (MAL) are pro-drugs that are quickly metabolized to protoporphyrin IX, a highly photosensitive molecule, in the mitochondrial biosynthetic pathway to haem. The photoactivation of protoporphyrin IX by visible light causes an intracellular oxidative stress that leads to apoptosis or necrosis. The selectivity for AK spots is high because the intact stratum corneum of the surrounding skin is quite impermeable to ALA and MAL, and, also, malignant keratinocytes have a higher metabolic activity. In addition, photoactivation of lymphocytes and other immune competent cells leads to a modulation of immune and inflammatory responses [23].

Concerning photodynamic therapy (PDT), two treatment protocols are available, although the treatment characteristics reported in Table 1 are the same. In "conventional" PDT, MAL or ALA cream is applied with an occlusive dressing for 3 hours and then the skin is exposed to a red light from an artificial source. It is effective but pain, stinging, and burning sensations are frequent and may be strong and even

Table 1 Characteristics of topical drug treatments available in Europe for multiple AKs as reported in their SmPC) that is approved by EMA

\begin{tabular}{|c|c|c|c|c|c|c|}
\hline Brand name & $\begin{array}{l}\text { Drug principle } \\
\text { and concentra- } \\
\text { tion }\end{array}$ & $\begin{array}{l}\text { Quantity per unit (box } \\
\text { of sachets or tube) }\end{array}$ & Treatment protocol & $\begin{array}{l}\text { Treated area } \\
\text { per applica- } \\
\text { tion }\end{array}$ & $\begin{array}{l}\text { Max. area treated in } 1 \\
\text { session }\end{array}$ & $\begin{array}{l}\text { Approved } \\
\text { Olsen } \\
\text { score }\end{array}$ \\
\hline $\begin{array}{l}\text { Metvix }{ }^{\circledR}, \text { Galderma, } \\
\text { Switzerland }\end{array}$ & MAL $16 \%$ & $2 \mathrm{~g}$ & $\begin{array}{l}\text { A session of PDT } \\
\text { repeated after } 3 \\
\text { months if needed }\end{array}$ & $200 \mathrm{~cm}^{2}$ & No maximum & I-II \\
\hline $\begin{array}{l}\text { Ameluz }{ }^{\circledR}, \text { Biofrontera, } \\
\text { Germany }\end{array}$ & ALA $7.8 \%$ & $2 \mathrm{~g}$ & $\begin{array}{l}\text { A session of PDT } \\
\text { repeated after } 3 \\
\text { months if needed. }\end{array}$ & $20 \mathrm{~cm}^{2}$ & No maximum & I-II \\
\hline $\begin{array}{l}\text { Efudix }^{\circledR} \text {, Valeant, } \\
\text { Canada }\end{array}$ & 5 -FU 5\% & $20 \mathrm{~g}$ & $\begin{array}{l}\text { 1-2 daily applications } \\
\text { for } 4 \text { weeks }\end{array}$ & N/A & $500 \mathrm{~cm}^{2}$ & I-III \\
\hline $\begin{array}{l}\text { Tolak }^{\circledR} \text {, Pierre Fabre } \\
\text { France }\end{array}$ & $5-\mathrm{FU} 4 \%$ & $40 \mathrm{~g}$ & $\begin{array}{l}\text { A daily application for } \\
4 \text { weeks }\end{array}$ & N/A & No maximum & I-III \\
\hline $\begin{array}{l}\text { Aldara }^{\circledR}, \text { Meda, } \\
\text { Sweden }\end{array}$ & IMI 5\% & $\begin{array}{l}12 \text { sachets containing } \\
250 \mathrm{mg} \text { cream each }\end{array}$ & $\begin{array}{l}\text { A daily application } 3 \\
\text { times per week x } 4 \\
\text { weeks (repeated after } \\
1 \text { month if needed) }\end{array}$ & $25 \mathrm{~cm}^{2}$ & $50 \mathrm{~cm}^{2}$ & I-II \\
\hline $\begin{array}{l}\text { Zyclara }^{\circledR}, \text { Meda, } \\
\text { Sweden }\end{array}$ & IMI $3.75 \%$ & $\begin{array}{l}28 \text { sachets containing } \\
250 \mathrm{mg} \text { cream each }\end{array}$ & $\begin{array}{l}\text { A daily application for } \\
2 \text { weeks followed } \\
\text { by } 2 \text { weeks rest and } \\
\text { other } 2 \text { weeks of } \\
\text { treatment }\end{array}$ & $200 \mathrm{~cm}^{2}$ & $\begin{array}{l}\text { face OR scalp }(\sim 300 \\
\left.\text { to } 400 \mathrm{~cm}^{2}\right)\end{array}$ & I-II \\
\hline $\begin{array}{l}\text { Solaraze }{ }^{\circledR}, \text { Almirall, } \\
\text { Spain }\end{array}$ & DHA $3 \%$ & 60 or $90 \mathrm{~g}$ & $\begin{array}{l}\text { Two daily applications } \\
\text { for } 90 \text { days }\end{array}$ & N/A & $200 \mathrm{~cm}^{2}$ & I-III \\
\hline $\begin{array}{l}\text { Klysiri }^{\circledR}, \text { Almirall, } \\
\text { Spain }\end{array}$ & TIR $1 \%$ & $\begin{array}{l}5 \text { sachets containing } \\
250 \mathrm{mg} \text { cream each }\end{array}$ & $\begin{array}{l}\text { A daily application for } \\
5 \text { consecutive days }\end{array}$ & $25 \mathrm{~cm}^{2}$ & $25 \mathrm{~cm}^{2}$ & I \\
\hline
\end{tabular}

Generic products with similar characteristic are available in some European Countries

$S m P C$ summary of product characteristics, EMA European Medicines Agency, $M A L$ methylamino levulinate, $A L A$ aminolevulinic acid, $F U$ fluorouracil, IMI imiquimod, DHA diclofenac and hyaluronic acid, TIR tirbanibulin 
intolerable [24]. Additionally, the availability of a red light source and the prolonged stay in the general practitioner's office are additional disadvantages.

More recently, daylight PDT has demonstrated similar efficacy with less pain and inflammation [25]. The treatment protocol is very simple: patients are exposed to direct or indirect solar radiation for 2 hours after a 30-minute application (without occlusion) of MAL/ALA cream. However, this treatment modality has the limitation that the light dose varies based on the combination of latitude, season, weather conditions, and hour of the day.

The use of a greenhouse has been suggested to mitigate the meteorological and environmental variability, but it is difficult to organize in many hospitals and, at lower latitudes, an air conditioning system is needed. As a possible solution to these limitations, indoor daylight PDT has been developed. The treatment protocol, efficacy, and tolerability are the same of conventional PDT but, differently from dlPDT, the skin is exposed to an artificial broad-band white light source indoors and not to direct sunlight outdoors [26].

Tirbanibulin (TIR) was recently approved by the European Medicines Agency and, at present, is being marketed in the UK, Germany, and the USA and it will likely be available in other European countries in a few months [27]. It is an inhibitor of Src kinase signaling and tubulin polymerisation that have been linked to $\mathrm{AK}$ onset and progressions to invasive SCC [27]. An additional drug, ingenol mebutate is not included in the present discussion because it was recently withdrawn after a warning of suspicious cancerogenic activity.

The main practical characteristics of the available preparations, i.e., the brand name (generic drugs with the same formulation are available in some European countries), the concentration of the active ingredient, the quantity per unit (box of sachets or tube), the treatment protocol (daily applications and duration of the treatment cycle), the area treated per application with one tube/sachet (summary of product characteristics), the maximal area treated in one session, and the approval status for the thickness of the AKs that can be treated are summarized in Table 1 [20-23, 28-31].

Photodynamic therapy is the only in-office drug treatment while all the others are home outpatient therapies that require active participation of the patient. The commitment required from the patient is one daily application with $4 \%$ 5-FU, TIR, 3.75\% IMI, and 5\% IMI (three times a week), one to two daily applications of 5\% 5-FU, and two daily applications of DHA. The size of the area with multiple AKs and the maximum area treated in each treatment cycle determine the overall duration of the treatment: treating large surfaces with treatments approved for small $\left(25-\mathrm{cm}^{2}\right)$ areas would require the physician to repeat consecutive cycles on adjacent areas, which can lead to an unacceptable overall treatment duration (Table 2). The size of the area can be easily calculated with three-dimensional cameras (Fig. 1) but, more practically, we can consider that the area of the temple is approximately $25 \mathrm{~cm}^{2}$, the nose $50 \mathrm{~cm}^{2}$, the cheek $100 \mathrm{~cm}^{2}$, the forehead $200 \mathrm{~cm}^{2}$, and the entire face or scalp $400 \mathrm{~cm}^{2}$ (Table 2) [32].

For example, the overall duration of treatment of a whole bald scalp is 1 day (plus another day if a retreatment is needed after 3 months) with PDT, 28 days with both 5\% and 4\% 5-FU, 90 days with IMI 3.75\%, 180 days with DHA, and 448 days with IMI 5\% (Table 2). However, for the treatment of smaller areas, such as the temple, the overall duration remains the same with PDT (1 day plus another day if a retreatment is needed after 3 months) and 5-FU (28 days) whereas it is lower with IMI 3.75\% (45 days), TIR (80 days), DHA (90 days), and IMI 5\% (28 days) (Table 2). The cost of the treatment is calculated by multiplying the cost for the number of packages that are required to fulfill the treatment cycle and it varies greatly in relation to the size of the area to be treated [33]. However, although the cost is an important issue for the national health systems, it is not relevant for the individual patients in European countries because the treatment is usually fully reimbursed.

\subsection{Efficacy, Toxicity, and Tolerability}

Although lesion-directed treatments are widely used, the present knowledge of their efficacy, tolerability, and cosmetic outcome is scarce. In a randomized controlled trial (RCT) studying cryotherapy vs PDT, the lesion response rate of cryotherapy was superior (75\%) but not in a statistically significant way, whereas the cosmetic results and patient preferences were significantly lower for cryotherapy [34].

In another RCT, cryotherapy was significantly more effective than $\mathrm{CO}_{2}$ laser ablation: 3 months after treatment the rates of complete remission (CR) for the single lesions were $78.2 \%$ and $72.4 \%$ respectively, whereas when considering "patients' CR" (as in remission of all the lesions) the gap was higher with $71.6 \%$ and $65.3 \%$, respectively. The "patients' CR" was also significantly higher at the 12-month follow-up visit with 53\% for cryotherapy and $14 \%$ for laser ablation. The cosmetic outcome was good or excellent in almost all patients after both treatments, without differences [19].

The only topical drug treatment that is available for the targeted treatment of lesions is a combination of $0.5 \%$ 5-FU and $10 \%$ salicylic acid (Actikerall ${ }^{\circledR}$; Almirall, Barcelona, Spain) [29]. It should be applied once daily until the lesions have completely cleared, or for up to a maximum of 12 weeks. A RCT of 5-FU/salicylic acid vs DHA and placebo found that the clearance rates of lesions were $74.5 \%, 54.6 \%$, and $35.5 \%$ and the complete clinical clearances of patients were $55.4 \%, 32.0 \%$, and $15.1 \%$ with 5-FU/salicylic acid, DHA, and placebo, respectively [35]. 
Table 2 Treatment duration (number of packages) by cancerization field size and allowing for the maximum treatment area per cycle, as reported in their SmPC that is approved by EMA

\begin{tabular}{|c|c|c|c|c|c|c|c|c|c|}
\hline \multicolumn{2}{|l|}{ Brand name } & Metvix $^{\circledR}$ & Ameluz $^{\circledR}$ & Efudix $^{\circledR}$ & Tolak $^{\circledR}$ & $\begin{array}{l}\text { Aldara }^{\circledR} \\
\text { (package with } 12 \\
\text { sachets) }\end{array}$ & $\begin{array}{l}\text { Solaraze }^{\circledR} \\
(90 \mathrm{~g} \text { tube })\end{array}$ & Zyclara $^{\circledR}$ & Klisyri $^{\circledR}$ \\
\hline \multicolumn{2}{|c|}{ Drug principle and concentration } & MAL $16 \%$ & ALA $7.8 \%$ & $5-\mathrm{FU} 5 \%$ & 5-FU 4\% & IMI 5\% & IMI $3.75 \%$ & DHA 3\% & TIR $1 \%$ \\
\hline \multicolumn{2}{|c|}{$\begin{array}{l}\text { Approved area per treatment cycle } \\
\qquad \begin{array}{l}\text { Approximated } \\
\text { skin area to be } \\
\text { treated }\end{array}\end{array}$} & $200 \mathrm{~cm}^{2}$ & $200 \mathrm{~cm}^{2}$ & $500 \mathrm{~cm}^{2}$ & ND & $25 \mathrm{~cm}^{2}$ & $200 \mathrm{~cm}^{2}$ & $200 \mathrm{~cm}^{2}$ & $25 \mathrm{~cm}^{2}$ \\
\hline Temple & $25 \mathrm{~cm}^{2}$ & $1(1)$ & $1(1)$ & $28(1)$ & $28(1)$ & $28(1)$ & $90(0.5)$ & $45(1)$ & $5(1)$ \\
\hline Nose & $50 \mathrm{~cm}^{2}$ & $1(1)$ & $1(1)$ & $28(1)$ & $28(1)$ & $56(2)$ & $90(1)$ & $45(1)$ & $10(2)$ \\
\hline Cheek & $100 \mathrm{~cm}^{2}$ & $1(1)$ & $1(1)$ & $28(1)$ & $28(1)$ & $112(4)$ & $90(2)$ & $45(1)$ & $20(4)$ \\
\hline Forehead & $200 \mathrm{~cm}^{2}$ & $1(1)$ & $1(1)$ & $28(4)$ & $28(2)$ & $224(8)$ & $90(4)$ & $45(1)$ & $40(8)$ \\
\hline Face OR Scalp & $400 \mathrm{~cm}^{2}$ & $1(2)$ & $1(2)$ & $28(7)$ & $28(4)$ & $448(16)$ & $180(8)$ & $90(2)$ & $80(16)$ \\
\hline
\end{tabular}

Average areas of head districts have been calculated in our clinic with a 3D camera (Visia Vectra, Canfield Scientific, Parsipanny, NJ) and the figure was rounded to the nearest full value

SmPC summary of product characteristics, EMA European Medicines Agency, $M A L$ methylamino levulinate, $A L A$ aminolevulinic acid, $F U$ fluorouracil, IMI imiquimod, DHA diclofenac and hyaluronic acid, TIR tirbanibulin
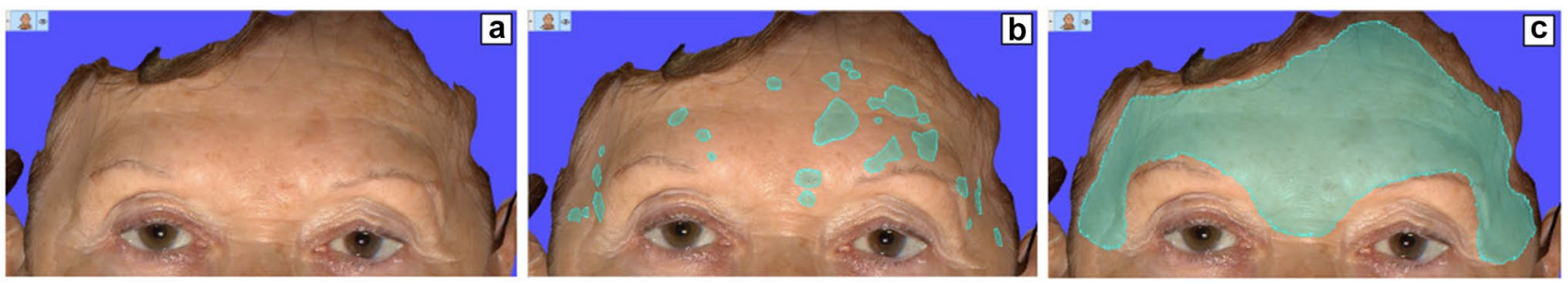

Fig. 1 Clinical appearance of a patient with multiple AK I and AK II [Olsen grading] (a), area of the actinic keratosis spots (b), and area of the cancerization field (c)

Unlike lesion-directed treatments, all field-directed drug treatments were investigated with well-designed placebo-controlled RCTs and all showed high efficacy and tolerability. However, the therapeutic choice would be facilitated if we had results of direct comparative studies. Unfortunately, RCTs with an active comparator are few and results were contrasting. In a study, 5\% IMI was more effective with a better cosmetic outcome compared with cryosurgery and 5\% 5-FU [36], and in another study, 5\% IMI was less effective than 5\% FU, and both were superior to MAL-PDT [37]. In a third study, MAL-PDT had better efficacy, cosmetic outcome, and patients' overall satisfaction in comparison with DHA [38].

Additionally, network meta-analyses (NMAs) of RCTs vs placebo do not show uniform results [7, 39-42] even if they agree that, in principle, 5\% 5-FU and MAL/ALA-PDT are the most effective treatments (> 65\% CR); 5\% IMI also has a good efficacy (>50\% CR) whereas DHA and 3.75\% IMI are the less effective ( $>35 \% \mathrm{CR}$ ). Differences in NMA conclusions may be largely related to the different treatment outcomes of RCTs [42]. Indeed, in a few studies, the endpoint was the patients' clearance rate and, in others, it was the lesions' clearance rate. In addition, both were sometimes calculated on the whole skin surface and other times on a $25-\mathrm{cm}^{2}$ reference area. Finally, the thickness and the size of treated AKs were different and recurrences were calculated after follow-ups of variable durations [42, 43].

ALA-PDT, MAL-PDT, and 5\% IMI are also associated with the highest significant long-term efficacy $(\geq 12$ months) [44] and a meta-analysis of interventions from postmarketing surveillance trials showed that PDT and 5-FU/ SA were more effective than DHA in terms of participant complete clearance rate, lesion-specific clearance rate, and sustained remission at follow-up [45]. The most widely used and authoritative guidelines and experts' recommendations from Europe agree that 5\% FU, 4\% FU, and both conventional PDT and daylight PDT with ALA and MAL are generally more effective than 3.75\% IMI and 5\% IMI, with DHA being on an even lower step; each treatment having a different strength of recommendations [6-8, 46, 47]. Frequency 
and intensity of adverse effects are mostly considered in direct relationship with efficacy, with DHA, 5\% IMI, and $3.75 \%$ IMI leading to a lower degree of inflammation, and conventional MAL or ALA-PDT, 5\% 5-FU, and 4\% 5-FU being more proinflammatory $[6,7,46,47]$. Daylight PDT is the only exception, being at the same time among the most effective treatments and the less proinflammatory as well [6, $7,46,47]$. A single NMA investigated patients' tolerability of treatments and compared the risk of withdrawals due to adverse events with the different medications: it reported a numerically (non-statistically significant) lower risk with $4 \%$ 5-FU, 5\% 5-FU, and 3.75\% IMI in comparison to DHA and 5\% IMI [40].

Treatment results with TIR are not discussed in guidelines and experts' recommendations because it has been recently approved. However, efficacy seems good with $44-54 \%$ of complete clearance and $68-76 \%$ of partial clearance after 2 months from the end of treatment. Approximately $35 \%$ of patients experience some adverse effect, but severe topical adverse effects were reported only in $<1 \%$ of patients [27].

Finally, we must emphasize that results of drug treatments apply only to AKs of the head or hands, whereas AKs located in other sites of the body have received little attention. Unlike the results of studies on the head and neck area, a NMA of the limited number of available studies on this topic showed that cryosurgery has the highest complete clearance rates in comparison to drug treatments, but the certainty of the evidence varied from very low to high and was limited by imprecision and study limitations [48].

Non-pharmacological treatments for multiple lesions and the cancerization field are chemical peelings, for example, phenols or trichloroacetic acid alone or in combination with Jessner's solution, and physical ablative techniques, for example, $\mathrm{CO}_{2}$ laser ablative fractional resurfacing [49] and cold atmospheric plasma using a microwave-driven argon plasma jet [50]. These are a practical alternative to drug treatments but, despite their long-standing usage, efficacy and safety have not been investigated in depth with large RCTs, and the optimal treatment protocol remains to be clarified.

\section{Oral and Topical Photoprotection and Chemoprevention of AKs}

A careful photoprotection should always be recommended to patients with multiple AKs. Therefore, we should keep recommending to patients the simple behaviors that are necessary to achieve this goal: search for the shadow, avoid sun exposures from 10 am to $3 \mathrm{pm}$, use a wide-brimmed hat and long-sleeved shirts outdoors, avoid artificial tanning, and, of the outmost importance, we should campaign to make people forget the cosmetic and "social" value of tanning
$[1,9,51,52]$. Sunscreens are the other pillar of prevention: their use is recommended by all guidelines [9, 51-53] as RCTs have demonstrated that sunscreen use reduces the occurrence of both AKs and SCCs [54-56]. The preventative action of sunscreens will likely be further increased by new filters with better photo-stability and water resistance [57] and will be able to shield not only UVB but also UVA and blue light, which have demonstrated mutagenic activity on keratinocytes [57, 58].

Oral photoprotection and chemoprevention treatments are also attracting increasing attention: oral nicotinamide (or niacinamide) is a low-cost compound that has demonstrated to both prevent and reduce the number of AKs in high-risk patients, i.e., patients who had at least two non melanoma skin cancers (NMSCs) in the previous 5 years [59]. Moreover, two earlier phase II studies showed that $500 \mathrm{mg}$ of oral nicotinamide taken once or twice daily in individuals with sun-damaged skin (four or more AKs and with or without a history of skin cancer) induced a 29\% (95\% confidence interval $11-44 ; p=0.005)$ and a $35 \%$ (95\% confidence interval 18-48; $p=0.0006$ ) relative reduction in AK count at 4 months, respectively [60]. Preliminary clinical findings suggest that also an extract of the fern Polypodium leucotomos, containing a mixture of antioxidants, has a chemopreventative activity against the development of AKs [61]. Moreover, the achievement of an optimal vitamin D blood level is often a major concern and a justification for excessive solar exposures for many older adults; however, the UV dose that is needed for this task is usually overestimated and oral supplementation is a valuable alternative [62].

\section{Management of the Older Patients with AKs}

Often, the physicians first task is to motivate the older (aged 60 years and more) patient to treat AKs, as many of them are not convinced about the reasons why their conditions need to be treated because they underestimate the risk of progression to cancer $[6,63]$ and have a lesser focus on pain, bleeding, discomfort, and cosmetic aspects of the condition (which are other among the main drivers of the decision to seek medical help in younger subjects) [6]. Additionally, they are often less motivated to treat their lesions by their physicians, relatives, and caregivers [63].

Once the patient is correctly informed and decides to undertake the treatment, the general practitioner should carefully evaluate which treatment is most suitable for the individual patient. The lesions' thickness and number are the most important criteria to be considered for the therapeutic choice, although lesion distribution is an important factor as well because hard-to-reach body locations may require the help of caregivers for the products' application. Isolated AKs 
should be removed with lesion-directed treatments: these are delivered in a single session at the general practitioner's office, and the patient and the caregivers should only engage in the medications during the quick recovery phase [34].

Although useful for didactic purposes, the schematic distinction between field-directed treatments and lesiondirected treatments does not reflect what happens in daily practice, where treatments are often combined. For example, a lesion-directed treatment is often used for the treatment of hyperkeratotic lesions of patients with multiple AKs before applying a field-directed treatment if not approved for AK III lesions; a lesion-directed treatment is also useful after a field treatment if one or more lesions have been resistant [64]. Conversely, a field treatment such as PDT is used if a patient with few isolated AKs requires an overall rejuvenation treatment of photo-aged skin [65]. Additionally, fielddirected treatments are needed in case of multiple lesions/ high AKASI scores because they not only address the clinically visible lesions, but also the subclinical lesions and the field of cancerization.

Randomized controlled trials, treatment guidelines, and NMAs provide information on the efficacy, safety, and tolerability of the treatment options and these notions do not seem to vary with increasing age, to the point that no dose adjustments and/or special precautions are required [20-23, 28-31]. High and sustained efficacy is particularly important in older patients because it reduces the risk of progression to SCC, and it reduces the likelihood of retreatment need as well. However, if a retreatment is needed, previous experience of good tolerability with infrequent and not serious adverse effects has the utmost importance in the treatment choice [66].

However, we must consider that tolerability does not depend only on the degree of the inflammatory reaction and on the intensity of pain, but also on their duration, which is proportional to the duration of the treatment cycle itself. For example, an intense inflammatory reaction for a short period of time could be preferred by some patients compared to a milder reaction that lasts for several weeks.

That said, high efficacy and tolerability cannot be the only drivers of the therapeutic choice: achievement of an optimal adherence for the entire duration of the treatment is required to avoid an unwanted treatment failure. Adherence is usually obtained by matching the patient's expectations, needs, and preferences in choosing the treatment that has the characteristics that are the most coherent with a patient's physical and mental capacity. The most common expectations of patients are a lack of impairment of daily activities when undertaking the treatment, the simplicity of applications, the short duration of the protocol, and the low frequency of treatments [63].

Several practical issues (e.g., the duration of the treatment cycle, the approval status for thick lesions, the number of daily applications, and the complexity of application [63]) must be evaluated by the physician according to his/her experience and skills, alongside data concerning efficacy and tolerability. This evaluation is particularly relevant when treating older subjects in a fragile condition like, for instance, when treating patients with mental impairment who cannot understand the treatment modality and/ or patients with a low physical capacity making it hard to comply with self-administered treatments and cope with side effects (such as pain and time to heal) [47, 67]. For these patients and for the many patients who ask for a treatment that is not performed at home, in-office treatments such as PDT, chemical peelings and physical treatments should be preferred [63]. If the patient needs a family or professional caregiver, his/her commitment and availability should be ascertained, and the importance of the correct use of topical medications should be thoroughly explained.

Another category needing special attention is drug-immunosuppressed patients, who need to be treated very carefully because of their greater risk of developing AKs and SCCs. Immediate primary preventive measures, with a very careful sun protection, and the early use of curative treatments are mandatory. In addition, they must be followed up for a long time because they have a higher risk of recurrences.

A final remark, which is last but not least, is the continuing need to improve general practitioners' awareness of the threat that AKs pose to patients' health. Indeed, many general practitioners have poor experience and knowledge of AKs, and they provide a limited proactive clinical assessment and/or follow-up care [68].

\section{Conclusions}

Actinic keratosis is a frequent skin problem of older subjects and it represents the biological precursor of SCC of the skin, a potentially life-threatening tumor. In addition, patients often complain of aesthetic impairment and bleeding.

The risk of malignant progression of the single lesion is low but it is not predictable on the basis of the clinical thickness and size. Therefore, all AKs should be treated and, if multiple lesions are present, the surrounding photodamaged skin should be treated as well because it harbors a "cancerization field" with keratinocytes bearing a heavy mutational burden that is a risk factor for the development of new lesions.

We have several treatment options: physical treatments, such as cryosurgery and laser, are suitable for isolated AKs whereas drug treatments are suggested for multiple AKs. Drugs are different with regard to mechanisms of action, pharmacology, safety profile, and treatment protocol and therefore the physician can individualize the treatment 
choice on the basis of the needs and skills of the patients to obtain the best adherence to treatment and, therefore, the optimal therapeutic result.

\section{Declarations}

Funding No sources of funding were received for the preparation of this article.

Conflicts of Interest/Competing Interests Piergiacomo Calzavara-Pinton was a consultant for LEO, Galderma, Almirall, Meda, Pierre Fabre, AbbVie, Sanofi, Cantabria, and Janssen. Irene Calzavara-Pinton, Chiara Rovati, and Maria Teresa Rossi have no conflicts of interest to disclosure.

Ethics Approval Not applicable.

Consent to Participate Not applicable.

Consent for Publication Not applicable.

Availability of Data and Material Not applicable.

Code Availability Not applicable.

Authors' Contributions All authors contributed equally to the literature search, data analysis, draft, and critical revision of the manuscript.

Open Access This article is licensed under a Creative Commons Attribution-NonCommercial 4.0 International License, which permits any non-commercial use, sharing, adaptation, distribution and reproduction in any medium or format, as long as you give appropriate credit to the original author(s) and the source, provide a link to the Creative Commons licence, and indicate if changes were made. The images or other third party material in this article are included in the article's Creative Commons licence, unless indicated otherwise in a credit line to the material. If material is not included in the article's Creative Commons licence and your intended use is not permitted by statutory regulation or exceeds the permitted use, you will need to obtain permission directly from the copyright holder. To view a copy of this licence, visit http://creativecommons.org/licenses/by-nc/4.0/.

\section{References}

1. Green AC. Epidemiology of actinic keratoses. Curr Probl Dermatol. 2015;46:1-7. https://doi.org/10.1159/000366525.

2. Schmitz L, Kahl P, Majores M, Bierhoff E, Stockfleth E, Dirschka T. Actinic keratosis: correlation between clinical and histological classification systems. J Eur Acad Dermatol Venereol. 2016;30:1303-7. https://doi.org/10.1111/jdv.13626.

3. Warino L, Tusa M, Camacho F, Teuschler H, Fleischer AB Jr, Feldman SR. Frequency and cost of actinic keratosis treatment. Dermatol Surg. 2006;32:1045-9. https://doi.org/10.1111/j. 1524-4725.2006.32228.x.

4. Dréno B, Amici JM, Basset-Seguin N, Cribier B, Claudel JP, Richard MA, et al. Management of actinic keratosis: a practical report and treatment algorithm from AKTeam ${ }^{\mathrm{TM}}$ expert clinicians. J Eur Acad Dermatol Venereol. 2014;28:1141-9. https:// doi.org/10.1111/jdv.12434.
5. Dodds A, Chia A, Shumack S. Actinic keratosis: rationale and management. Dermatol Ther (Heidelb). 2014;4:11-31. https:// doi.org/10.1007/s13555-014-0049-y.

6. Calzavara-Pinton P, Hædersdal M, Barber K, Basset-Seguin N, Del Pino Flores ME, Foley P, et al. Structured expert consensus on actinic keratosis: treatment algorithm focusing on daylight PDT. J Cutan Med Surg. 2017;21:3S-16S. https://doi.org/10. 1177/1203475417702994.

7. Leiter U, Heppt MV, Steeb T, Amaral T, Bauer A, Becker JC, et al. S3 guideline for actinic keratosis and cutaneous squamous cell carcinoma ( $\mathrm{cSCC}$ ): short version, part 2: epidemiology, surgical and systemic treatment of cSCC, follow-up, prevention and occupational disease. J Dtsch Dermatol Ges. 2020;18:40013. https://doi.org/10.1111/ddg.14072.

8. Cancer Council Australia Keratinoyte Cancer Guidelines Working Party. Clinical practice guidelines for keratinoyte cancer. 25 November 2019. Sydney: Cancer Council Australia. https:// wiki.cancer.org.au/australia/Guidelines:Keratinocyte_carci noma. Accessed 27 Jan 2022.

9. de Berker D, McGregor JM, Hughes BR, British Association of Dermatologists Therapy Guidelines and Audit Subcommittee. Guidelines for the management of actinic keratoses. Br J Dermatol. 2007;156:222-30. https://doi.org/10.1111/j.1365-2133. 2006.07692.x.

10. Roewert-Huber J, Stockfleth E, Kerl H. Pathology and pathobiology of actinic (solar) keratosis: an update. Br J Dermatol. 2007;157:18-20. https://doi.org/10.1111/j.1365-2133.2007. 08267.x.

11. Schmitz L, Gambichler T, Gupta G, Stücker M, Stockfleth E, Szeimies RM, et al. Actinic keratoses show variable histological basal growth patterns: a proposed classification adjustment. J Eur Acad Dermatol Venereol. 2018;32:745-51. https://doi.org/ $10.1111 / j d v .14512$.

12. Mittelbronn MA, Mullins DL, Ramos-Caro FA, Flowers FP. Frequency of pre-existing actinic keratosis in cutaneous squamous cell carcinoma. Int J Dermatol. 1998;37:677-81. https:// doi.org/10.1046/j.1365-4362.1998.00467.x.

13. Werner RN, Sammain A, Erdmann R, Hartmann V, Stockfleth E, Nast A. The natural history of actinic keratosis: a systematic review. Br J Dermatol. 2013;169:502-18. https://doi.org/10. 1111/bjd.12420.

14. Fernandez Figueras MT. From actinic keratosis to squamous cell carcinoma: pathophysiology revisited. J Eur Acad Dermatol Venereol. 2017;31:5-7. https://doi.org/10.1111/jdv.14151.

15. Dirschka T, Pellacani G, Micali G, Malvehy J, Stratigos AJ, Casari A, et al. A proposed scoring system for assessing the severity of actinic keratosis on the head: actinic keratosis area and severity index. J Eur Acad Dermatol Venereol. 2017;31:1295-302. https://doi.org/10.1111/jdv.14267.

16. Schmitz L, Gambichler T, Gupta G, Stücker M, Dirschka T. Actinic Keratosis Area and Severity Index (AKASI) is associated with the incidence of squamous cell carcinoma. J Eur Acad Dermatol Venereol. 2018;32:752-6. https://doi.org/10.1111/jdv. 14682.

17. Alomar A, Stockfleth E, Dirschka T, Gupta G, Aractingi S, Dakovic $R$, et al. Efficacy and safety of imiquimod 3.75\% from Lmax in actinic keratosis according to Fitzpatrick skin type. J Drugs Dermatol. 2016;15:285-9.

18. Fernández-Figueras MT, Carrato C, Sáenz X, Puig L, Musulen E, Ferrándiz C, et al. Actinic keratosis with atypical basal cells (AK I) is the most common lesion associated with invasive squamous cell carcinoma of the skin. J Eur Acad Dermatol Venereol. 2015;29:991-7. https://doi.org/10.1111/jdv.12848.

19. Zane C, Facchinetti E, Rossi MT, Specchia C, Ortel B, CalzavaraPinton P. Cryotherapy is preferable to ablative $\mathrm{CO}_{2}$ laser for the treatment of isolated actinic keratoses of the face and scalp: a 
randomized clinical trial. Br J Dermatol. 2014;170:1114-21. https://doi.org/10.1111/bjd.12847.

20. Meda Pharmaceuticals. Efudix cream: summary of product characteristics. 2015. http://www.medicines.org.uk/emc/medicine/ 6219/SPC/Efudix+Cream. Accessed 17 Nov 2015.

21. Meda Pharmaceuticals. Zyclara 3.75\% cream: summary of product characteristics. 2015. https://www.medicines.org.uk/emc/medic ine/27323. Accessed 17 Nov 2015.

22. Almirall. Actikerall $5 \mathrm{mg} / \mathrm{g}+100 \mathrm{mg} / \mathrm{g}$ cutaneous solution: summary of product characteristics. 2015. http://www.medicines.org. uk/emc/medicine/24614. Accessed 17 Nov 2015.

23. Galderma. Metvix $160 \mathrm{mg} / \mathrm{g}$ cream: summary of product characteristics. 2015. https://www.medicines.org.uk/emc/medicine/ 11913. Accessed 17 Nov 2015.

24. Calzavara-Pinton PG, Rossi MT, Sala R, Italian Group For Photodynamic Therapy. A retrospective analysis of real-life practice of off-label photodynamic therapy using methyl aminolevulinate (MAL-PDT) in 20 Italian dermatology departments. Part 2: oncologic and infectious indications. Photochem Photobiol Sci. 2013;12:158-65. https://doi.org/10.1039/c2pp25125f.

25. Dirschka T, Ekanayake-Bohlig S, Dominicus R, Aschoff R, Herrera-Ceballos E, Botella-Estrada $\mathrm{R}$, et al. A randomized, intraindividual, non-inferiority, phase III study comparing daylight photodynamic therapy with BF-200 ALA gel and MAL cream for the treatment of actinic keratosis. J Eur Acad Dermatol Venereol. 2019;33:288-97. https://doi.org/10.1111/jdv.15185.

26. Arisi M, Rossi MT, Spiazzi L, Pisani EG, Venturuzzo A, Rovati $\mathrm{C}$, et al. A randomized split-face clinical trial of conventional vs indoor-daylight photodynamic therapy for the treatment of multiple actinic keratosis of the face and scalp and photoaging. J Dermatolog Treat. 2021;28:1-7. https://doi.org/10.1080/09546 634.2021.1944594.

27. Blauvelt A, Kempers S, Lain E, Schlesinger T, Tyring S, Forman $\mathrm{S}$, et al. Phase 3 trials of tirbanibulin ointment for actinic keratosis. N Engl J Med. 2021;384:512-20. https://doi.org/10.1056/ NEJMoa2024040.

28. Meda Pharmaceuticals. Aldara 5\% cream: summary of product characteristics. 2015. https://www.medicines.org.uk/emc/medic ine/8. Accessed 17 Nov 2015.

29. French Society of Dermatology. Guidelines for the diagnosis and treatment of cutaneous squamous cell carcinoma and precursor lesions. Arguments: May 2009. Ann Dermatol Venereol. 2009;136(Suppl. 5):S189-242.

30. Almirall. Solaraze gel: summary of product characteristics. 2015. https://www.medicines.org.uk/emc/medicine/21229. Accessed 17 Nov 2015.

31. Biofrontera Pharma GmbH. Ameluz $78 \mathrm{mg} / \mathrm{g}$ gel: summary of product characteristics. 2013. http://www.medicines.org.uk/ emc/medicine/27817. Accessed 17 Nov 2015.

32. Genovese G, Fai D, Fai C, Mavilia L, Mercuri SR. Daylight methyl-aminolevulinate photodynamic therapy versus ingenol mebutate for the treatment of actinic keratoses: an intraindividual comparative analysis. Dermatol Ther. 2016;29:191-6. https://doi.org/10.1111/dth.12334.

33. Calzavara-Pinton P, Zane C, Arisi M, Hamon PA, Tanova NT. Evaluation of the costs of topical treatments for actinic keratosis based on lesion response and the affected area. G Ital Dermatol Venereol. 2018;153:764-75. https://doi.org/10.23736/S03920488.18.06071-6.

34. Szeimies RM, Karrer S, Radakovic-Fijan S, Tanew A, Calzavara-Pinton $\mathrm{PG}, \mathrm{Zane} \mathrm{C}$, et al. Photodynamic therapy using topical methyl 5-aminolevulinate compared with cryotherapy for actinic keratosis: a prospective, randomized study. J Am Acad Dermatol. 2002;47:258-62.

35. Stockfleth E, Kerl H, Zwingers T, Willers C. Low-dose 5-fluorouracil in combination with salicylic acid as a new lesion-directed option to treat topically actinic keratoses: histological and clinical study results. Br J Dermatol. 2011;165:1101-8. https://doi. org/10.1111/j.1365-2133.2011.10387.x.

36. Krawtchenko N, Roewert-Huber J, Ulrich M, Mann I, Sterry $\mathrm{W}$, Stockfleth E. A randomised study of topical 5\% imiquimod vs. topical 5-fluorouracil vs. cryosurgery in immunocompetent patients with actinic keratoses: a comparison of clinical and histological outcomes including 1-year follow-up. Br J Dermatol. 2007;157:34-40. https://doi.org/10.1111/j.1365-2133.2007. 08271.x.

37. Jansen MHE, Kessels JPHM, Nelemans PJ, Kouloubis N, Arits AHMM, van Pelt HPA, et al. Randomized trial of four treatment approaches for actinic keratosis. N Engl J Med. 2019;380:93546. https://doi.org/10.1056/NEJMoa1811850.

38. Calzavara-Pinton P, Tanova N, Hamon P. Evaluation of the treatment costs and duration of topical treatments for multiple actinic keratosis based on the area of the cancerization field and not on the number of lesions. J Eur Acad Dermatol Venereol. 2019;33:312-7. https://doi.org/10.1111/jdv.15269.

39. Vegter S, Tolley K. A network meta-analysis of the relative efficacy of treatments for actinic keratosis of the face or scalp in Europe. PLoS ONE. 2014;9: e96829. https://doi.org/10.1371/ journal.pone.0096829.

40. Ezzedine K, Painchault C, Brignone M. Systematic literature review and network meta-analysis of the efficacy and acceptability of interventions in actinic keratoses. Acta Derm Venereol. 2021;101:adv00358. https://doi.org/10.2340/00015555-3690.

41. Gupta AK, Paquet M. Network meta-analysis of the outcome 'participant complete clearance' in nonimmunosuppressed participants of eight interventions for actinic keratosis: a follow-up on a Cochrane review. Br J Dermatol. 2013;169:250-9. https:// doi.org/10.1111/bjd.12343.

42. Eisen DB, Asgari MM, Bennett DD, Connolly SM, Dellavalle RP, Freeman EE, et al. Guidelines of care for the management of actinic keratosis. J Am Acad Dermatol. 2021;85:e209-33. https://doi.org/10.1016/j.jaad.2021.02.082.

43. Reynolds KA, Schlessinger DI, Vasic J, Iyengar S, Qaseem Y, Behshad R, et al. Core outcome set for actinic keratosis clinical trials. JAMA Dermatol. 2020;156:326-33. https://doi.org/10. 1001/jamadermatol.2019.4212.

44. Steeb T, Wessely A, Petzold A, Brinker TJ, Schmitz L, Leiter U, et al. Evaluation of long-term clearance rates of interventions for actinic keratosis: a systematic review and network metaanalysis. JAMA Dermatol. 2021;157:1066-77. https://doi.org/ 10.1001/jamadermatol.2021.2779.

45. Steeb T, Wessely A, Harlaß M, Heppt F, Koch EAT, Leiter U, et al. A systematic review and meta-analysis of interventions for actinic keratosis from post-marketing surveillance trials. J Clin Med. 2020;9:2253. https://doi.org/10.3390/jcm9072253.

46. Werner RN, Stockfleth E, Connolly SM, Correia O, Erdmann R, Foley P, et al. Evidence- and consensus-based (S3) guidelines for the treatment of actinic keratosis: International League of Dermatological Societies in cooperation with the European Dermatology Forum: short version. J Eur Acad Dermatol Venereol. 2015;29:2069-79. https://doi.org/10.1111/jdv.13180.

47. Peris K, Calzavara-Pinton PG, Neri L, Girolomoni G, Malara G, Parodi A, et al. Italian expert consensus for the management of actinic keratosis in immunocompetent patients. J Eur Acad Dermatol Venereol. 2016;30:1077-84. https://doi.org/10.1111/jdv. 13648.

48. Steeb T, Wessely A, Schmitz L, Heppt F, Kirchberger MC, Berking $\mathrm{C}$, et al. Interventions for actinic keratosis in nonscalp and nonface localizations: results from a systematic review with network meta-analysis. J Invest Dermatol. 2021;141:345-54. https:// doi.org/10.1016/j.jid.2020.06.021. 
49. Miller MB, Padilla A. $\mathrm{CO}_{2}$ laser ablative fractional resurfacing photodynamic therapy for actinic keratosis and nonmelanoma skin cancer: a randomized split-side study. Cutis. 2020;105(5):251-4.

50. Steeb T, Koch EAT, Wessely A, Wiest LG, Schmitz L, Berking $\mathrm{C}$, et al. Chemical peelings for the treatment of actinic keratosis: a systematic review and meta-analysis. J Eur Acad Dermatol Venereol. 2021;35:641-9. https://doi.org/10.1111/jdv.16844.

51. Werner RN, Jacobs A, Rosumeck S, Erdmann R, Sporbeck B, Nast A. Methods and results report: evidence and consensus-based (S3) guidelines for the treatment of actinic keratosis: International League of Dermatological Societies in cooperation with the European Dermatology Forum. J Eur Acad Dermatol Venereol. 2015;29:e1-66. https://doi.org/10.1111/jdv.13179.

52. Bonerandi JJ, Beauvillain C, Caquant L, Chassagne JF, Chaussade $\mathrm{V}$, Clavère $\mathrm{P}$, et al. Guidelines for the diagnosis and treatment of cutaneous squamous cell carcinoma and precursor lesions. J Eur Acad Dermatol Venereol. 2011;25:1-51. https://doi.org/10.1111/j. 1468-3083.2011.04296.x.

53. Tierney P, de Gruijl FR, Ibbotson S, Moseley H. Predicted increased risk of squamous cell carcinoma induction associated with sunbed exposure habits. Br J Dermatol. 2015;173:201-8. https://doi.org/10.1111/bjd.13714.

54. Naylor MF, Boyd A, Smith DW, Cameron GS, Hubbard D, Neldner KH. High sun protection factor sunscreens in the suppression of actinic neoplasia. Arch Dermatol. 1995;131:170-5.

55. Thompson SC, Jolley D, Marks R. Reduction of solar keratoses by regular sunscreen use. N Engl J Med. 1993;329:1147-51. https:// doi.org/10.1056/NEJM199310143291602.

56. van der Pols JC, Williams GM, Pandeya N, Logan V, Green AC. Prolonged prevention of squamous cell carcinoma of the skin by regular sunscreen use. Cancer Epidemiol Biomark Prev. 2006;15:2546-8. https://doi.org/10.1158/1055-9965.EPI-06-0352.

57. Calzavara-Pinton P, Ortel B, Venturini M. Non-melanoma skin cancer, sun exposure and sun protection. G Ital Dermatol Venereol. 2015;150:369-78.

58. Chamayou-Robert C, DiGiorgio C, Brack O, Doucet O. Blue light induces DNA damage in normal human skin keratinocytes. Photodermatol Photoimmunol Photomed. 2022;38:69-75. https://doi. org/10.1111/phpp.12718.

59. Chen AC, Martin AJ, Choy B, Fernández-Peñas P, Dalziell RA, McKenzie CA, et al. A phase 3 randomized trial of nicotinamide for skin-cancer chemoprevention. N Engl J Med. 2015;373:161826. https://doi.org/10.1056/NEJMoa1506197.

60. Surjana D, Halliday GM, Martin AJ, Moloney FJ, Damian DL. Oral nicotinamide reduces actinic keratoses in phase II double-blinded randomized controlled trials. J Invest Dermatol. 2012;132:1497-500. https://doi.org/10.1038/jid.2011.459.

61. Auriemma M, Di Nicola M, Gonzalez S, Piaserico S, Capo A, Amerio P. Polypodium leucotomos supplementation in the treatment of scalp actinic keratosis: could it improve the efficacy of photodynamic therapy? Dermatol Surg. 2015;41:898-902. https:// doi.org/10.1097/DSS.0000000000000425.

62. Holick MF. Vitamin D deficiency. N Engl J Med. 2007;357(3):266-81. https://doi.org/10.1056/NEJMra070553.

63. Steeb T, Wessely A, von Bubnoff D, Dirschka T, Drexler K, Falkenberg $\mathrm{C}$, et al. Treatment motivations and expectations in patients with actinic keratosis: a German-wide multicenter, cross-sectional trial. J Clin Med. 2020;9:1438. https://doi.org/10.3390/jcm90 51438.

64. Heppt MV, Steeb T, Ruzicka T, Berking C. Cryosurgery combined with topical interventions for actinic keratosis: a systematic review and meta-analysis. Br J Dermatol. 2019;180:740-8. https:// doi.org/10.1111/bjd.17435.

65. Morton CA, Szeimies RM, Basset-Séguin N, Calzavara-Pinton PG, Gilaberte Y, Haedersdal M, et al. European Dermatology Forum guidelines on topical photodynamic therapy 2019 Part 2: emerging indications: field cancerization, photorejuvenation and inflammatory/infective dermatoses. J Eur Acad Dermatol Venereol. 2020;34:17-29. https://doi.org/10.1111/jdv.16044.

66. Ceilley RI, Jorizzo JL. Current issues in the management of actinic keratosis. J Am Acad Dermatol. 2013;68:S28-38. https:// doi.org/10.1016/j.jaad.2012.09.051.

67. Esmann S, Jemec GB. Patients' perceptions of topical treatments of actinic keratosis. J Dermatolog Treat. 2014;25:375-9. https:// doi.org/10.3109/09546634.2012.757285.

68. Noels EC, Lugtenberg M, van Egmond S, Droger SM, Buis PAJ, Nijsten T, et al. Insight into the management of actinic keratosis: a qualitative interview study among general practitioners and dermatologists. Br J Dermatol. 2019;181:96-104. https://doi.org/10. 1111/bjd.17818. 